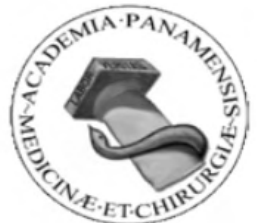

\title{
Editorial
}

\section{La Actividad Científica en Panamá}

The Scientific Activity in Panama

\section{Cuero César. APMC.*}

*Editor en jefe, Revista Médica de Panamá

\section{Palabras claves:}

producción científica

\section{Key words:}

scientific production

Correspondencia a:

Dr. César Cuero.

Correo electrónico: ccuero@cwpanama.net
Hasta hace poco tiempo la producción científica en el país era muy pobre. Una generación henchida de amor a la patria y a la ciencia, se sacrificó y marco el sendero que la siguiente generación siguió para llegar a donde estamos al presente.

Llama la atención que esos primeros patriotas, pudiendo quedarse en los lugares donde se formaron, prefirieron venir a su tierra, a trabajar en la nada, con casi nada, para sembrar en el corazón de todos los panameños el verdadero amor a la patria, no con palabras sino con hechos concretos. Con tenacidad y resolución comenzaron su labor científica, poniendo un ladrillo al lado del otro para dejar bien cimentada la obra que comenzaron.

En el caso de Panamá, algunos factores han contribuido positivamente a esta labor. El hecho de tener una escuela de Medicina, que a su vez giraba alrededor del Hospital Santo Tomás, que sirvió de semillero de formación de las generaciones de médicos con grado de excelencia y que a su vez contribuyeron a la formación de otros haciendo así escuela, permitieron que esa semilla de amor a la ciencia, fuera creciendo segura y firme.

Otro elemento que empujó en la dirección correcta esta obra, sin duda, fue el contar con una colmena esencialmente científica y de investigación como el Instituto Gorgas donde connotados científicos norteamericanos llegaron para realizar investigaciones en el campo de la medicina tropical, y enseñaron a despiertos investigadores locales el arte del quehacer científico. Dirigido primeramente por lo mejor de esos científicos que llegaron al istmo, siguió su labor de investigación por muchos años. Hoy, transformado en el Instituto Gorgas Para Estudios de la Salud, (ICGES) ya administrado por científicos panameños, continúa esa labor de investigación en el campo de la salud, sirviendo de casa a los investigadores modernos con los que cuenta el país.

Al presente, junto al ICGES, se cuenta con la entidad estatal: Secretaria Nacional de Ciencia, Tecnología e Innovación, SENACYT, que coordina todo el esfuerzo investigativo y de formación de investigadores, elemento indispensable, que está contribuyendo al progreso de la investigación científica en Panamá, en conjunto con el Instituto de Investigaciones Científica de Alta Tecnología, INDICASAT, donde se llevan a cabo estudios de investigación de primer nivel científico.

El panorama ahora es mejor, el horizonte más amplio, lo que ha llevado a colocar a Panamá, en el concierto de naciones con escuelas de investigación de primer nivel. Pero falta más, hay que seguir formando investigadores, hay que aumentar el presupuesto estatal y de la empresa privada que permita el avance de la ciencia. Hay que hacer de esta actividad del conocimiento humano una rutina establecida, con el apoyo necesario, para que nuestros científicos puedan realizar sus labores tranquilos, sintiéndose respaldados por el estado.

Esa es la meta y hacia allá nos encaminamos.
Órgano oficial de la Academia Panameña de Medicina y Cirugía y del Instituto Commemorativo Gorgas para Estudios de la Salud (ICGES). Indexado en LILACS Y EBSCO.
R M P

2019: Volumen 39(1): 1 